\title{
Nectar-dwelling microbes of common tansy are attractive to its mosquito pollinator, Culex pipiens L.
}

D. A. H. Peach ${ }^{1,2^{*}}$ D, C. Carroll' ${ }^{1}$, S. Meraj ${ }^{1}$, S. Gomes ${ }^{1}$, E. Galloway ${ }^{1}$, A. Balcita ${ }^{1,3}$, H. Coatsworth ${ }^{1,4}$, N. Young ${ }^{1}$, Y. Uriel ${ }^{1}$, R. Gries ${ }^{1}$, C. Lowenberger ${ }^{1}$, M. Moore ${ }^{1}$ and G. Gries ${ }^{1}$

\begin{abstract}
Background: There is widespread interkingdom signalling between insects and microbes. For example, microbes found in floral nectar may modify its nutritional composition and produce odorants that alter the floral odor bouquet which may attract insect pollinators. Mosquitoes consume nectar and can pollinate flowers. We identified microbes isolated from nectar of common tansy, Tanacetum vulgare, elucidated the microbial odorants, and tested their ability to attract the common house mosquito, Culex pipiens.

Results: We collected 19 microbial isolates from T. vulgare nectar, representing at least 12 different taxa which we identified with $16 \mathrm{~S}$ or $26 \mathrm{~S}$ rDNA sequencing as well as by biochemical and physiological tests. Three microorganisms (Lachancea thermotolerans, Micrococcus lactis, Micrococcus luteus) were grown on culture medium and tested in bioassays. Only the yeast L. thermotolerans grown on nectar, malt extract agar, or in synthetic nectar broth significantly attracted CX. pipiens females. The odorant profile produced by L. thermotolerans varied with the nutritional composition of the culture medium. All three microbes grown separately, but presented concurrently, attracted fewer $C x$. pipiens females than $L$. thermotolerans by itself.

Conclusions: Floral nectar of T. vulgare contains various microbes whose odorants contribute to the odor profile of inflorescences. In addition, L. thermotolerans produced odorants that attract $C$. pipiens females. As the odor profile of L. thermotolerans varied with the composition of the culture medium, we hypothesize that microbe odorants inform nectar-foraging mosquitoes about the availability of certain macro-nutrients which, in turn, affect foraging decisions by mosquitoes.
\end{abstract}

Keywords: Mosquitoes, Culex pipiens, Mosquito sugar feeding, Nectar microbes, Microbial volatiles, Insect-microbe interactions

\section{Background}

Chemical signalling between microbes and insects is widespread and occurs in a variety of contexts [1-3]. Plant odorants as well as visual displays of inflorescences play essential roles in attracting insect pollinators [4].

\footnotetext{
*Correspondence: dan@danpeach.net

1 Simon Fraser University, 8888 University Drive, Burnaby, BC, Canada

Full list of author information is available at the end of the article
}

Floral nectar provides nutrition and habitat for myriad microorganisms [5-10] that may ultimately alter the composition of nectar [11] and produce odorants [8, $12,13]$, thereby modifying the inflorescence odor bouquet [13-15]. These microbially-derived odorants may contribute to the plant-pollinator signalling system by serving as attractive semiochemicals (message-bearing chemicals) to pollinators [13, 16-18]. However, this type of signalling may be species-specific with respect to both the sender and the receiver of these semiochemicals 
because in other instances, microbe-derived odorants cause no behavioral response [19], or avoidance by pollinators $[19,20]$. Furthermore, the overall odor bouquet produced by microbes varies with the composition of the microbe community $[2,21]$, likely modifying the insects' behavioural responses.

Plant-derived nutrients (e.g., sugars) are fundamental dietary constituents for adult mosquitoes [22], providing energy for flight, mating, blood-feeding, egg-laying, and female overwintering [22-25]. Floral nectar is the dominant source of plant sugar for most mosquitoes but other sugar sources such as extra-floral nectar, aphid honeydew, and fruit juices are also consumed [22, 26]. Inflorescence semiochemicals [27] along with visual inflorescence displays [28] and $\mathrm{CO}_{2}$ [29] attract mosquitoes to various inflorescences [22, 29-31] that they distinguish by scent $[32,33]$ and may pollinate [34-37].

Microbe-derived odorants have not yet been implicated in mosquito nectar-foraging but are exploited by mosquitoes in a variety of other contexts. For example, the odor bouquet of microbe-inoculated or infested aphid honeydew is more attractive to the yellow fever mosquito, Aedes aegypti, than the odor bouquet of sterilized honeydew [38]. The volatile semiochemicals emitted by human skin microbes help attract host-seeking mosquitoes [39-41]. Carbon dioxide is another important vertebrate- and plant-host cue for mosquitoes [29, 42], which originates not only from potential hosts but also from their symbiotic microbes [43]. Moreover, microbe-derived semiochemicals indicate suitable oviposition sites for many mosquito species and attract gravid females [44-46]. Microbe-derived semiochemicals and $\mathrm{CO}_{2}$ may also play a role in mosquito attraction to floral nectar.

Common tansies, Tanacetum vulgare, are visited by many insect taxa [37, 47], including mosquitoes [37, 48] that respond to floral semiochemicals [29] and serve as pollinators [37]. Therefore, T. vulgare is a good model plant to investigate the role of nectar-dwelling microbes in the attraction of mosquitoes to floral nectar. Working with T. vulgare, and one of its mosquito pollinators, the common house mosquito, Culex pipiens [37], we tested the hypotheses $(\mathrm{H})$ that: $(1)$ nectar-colonizing microbes emit semiochemicals attractive to Cx. pipiens; (2) the attractiveness of these microbes is dependent upon their nutrient source; and (3) multiple species of nectar-colonizing microbes attract more mosquitoes than a single species.

Table 1 (i) List of microbes identified from Tanacetum vulgare nectar including information about the plant, inflorescence, and individual florets from which they were collected, (ii) the medium used to culture microbes, and iii the methods used for microbe identification

\begin{tabular}{|c|c|c|c|c|c|c|c|}
\hline \multirow[b]{2}{*}{ Isolate } & \multirow[b]{2}{*}{ Plate Media } & \multirow[b]{2}{*}{ Name of Microbe } & \multicolumn{3}{|l|}{ Source } & \multirow[b]{2}{*}{ ID Method } & \multirow[b]{2}{*}{ Accession \# } \\
\hline & & & Plant \# & Inflorescence \# & Floret \# & & \\
\hline LB-T1D1 & LB & $\begin{array}{l}\text { Mix of Bacillus amyloliquefaciens } \\
\& \text { B. subtilis }\end{array}$ & 1 & 1 & 1 & PCR + test & $\begin{array}{l}\text { MW539056 } \\
\text { MW538945 }\end{array}$ \\
\hline LB-T1E1 & LB & Pseudarthrobacter sp. & 1 & 2 & 1 & PCR & MW539063 \\
\hline LB-T1E2 & LB & Micrococcus lactis & 1 & 2 & 2 & $P C R+$ test & MW539682 \\
\hline LB-T2C1 & LB & Pseudomonas sp. & 2 & 1 & 1 & PCR & MW555319 \\
\hline LB-T2E1 & LB & Staphylococcus epidermidis & 2 & 1 & 1 & PCR & MW540426 \\
\hline LB-T3A1 & LB & Cryptococcus sp. & 3 & 1 & 1 & PCR & MW555579 \\
\hline LB-T3B2 & LB & Bacillus sp. & 3 & 2 & 1 & PCR & MW540653 \\
\hline LB-T4A2 & $L B$ & Rhodotorula/Ustilentyloma sp. & 4 & 1 & 1 & PCR & MW540505 \\
\hline LB-T4B1 & LB & Bacillus circulans & 4 & 2 & 1 & $P C R+$ test & MW540503 \\
\hline LB-T4B2 & LB & Bacillus sp. & 4 & 2 & 2 & PCR & MW540792 \\
\hline LB-T4C1 & LB & Micrococcus luteus & 4 & 3 & 1 & $P C R+$ test & MW540513 \\
\hline LB-T4D1 & LB & Bacillus sp. & 4 & 3 & 1 & PCR & MW540520 \\
\hline YPD-T1B1 & YEPD & Lachancea thermotolerans & 1 & 3 & 1 & PCR & MW540525 \\
\hline YPD-T1E1 & YEPD & Micrococcus sp. & 1 & 2 & 1 & $P C R$ & MW555329 \\
\hline YPD-T2E1 & YEPD & Lachancea thermotolerans & 2 & 2 & 2 & $P C R+$ test & MW540529 \\
\hline YPD-T3A1 & YEPD & Micrococcus sp. & 3 & 1 & 1 & PCR & MW555327 \\
\hline YPD-T3B2 & YEPD & Bacillus sp. & 3 & 2 & 1 & $P C R$ & MW540532 \\
\hline YPD-T4C1 & YEPD & Bacillus sp. & 4 & 3 & 1 & PCR & MW540612 \\
\hline
\end{tabular}




\section{Results}

\section{Identification of nectar-colonizing microbes}

We collected nectar from nectaries of $T$. vulgare florets with a sterile glass microcapillary tube and identified 19 microbial isolates (Table 1) by sequencing the $16 \mathrm{~S}$ or $26 \mathrm{~S}$ rDNA genes, and by comparing the results to data in the National Center for Biotechnology Information GenBank using BLASTn (Bethesda, USA; http://www.ncbu.nlm. nih.gov/BLAST.cgi). We performed additional biochemical and physiological tests on select isolates to aid in their identification (Table 2). Sampling a total of 40 florets from 20 inflorescences ( 2 florets per inflorescence) from 4 plants (5 inflorescences per plant), we found the yeast L. thermotolerans in nectar from two separate florets on two separate plants. Bacillus spp. were present in six florets from three separate plants, and Micrococcus spp. were present in four florets from three separate plants. In five floret samples, more than one microbe was present.

H1: Nectar-colonizing microbes emit odorants attractive to Cx pipiens
In two-choice laboratory experiments with a pairedtrap design, we tested attraction of female $C x$. pipiens to a synthetic nectar broth $(10 \% \mathrm{w} / \mathrm{v}$ sucrose, $2 \% \mathrm{w} / \mathrm{v}$ yeast extract) (control stimulus) and the same broth inoculated with (i) L. thermotolerans (Exp. 1), (ii) M. luteus (Exp. 2), or (iii) M. lactis (Exp. 3). We captured more female $C x$. pipiens when $L$. thermotolerans was the inoculum $(\mathrm{z}=4.03, \mathrm{p}<0.0001$; Fig. 1, Exp. 1) but not when either $M$. luteus or M. lactis was the inoculum (M. luteus: $\mathrm{z}=1.44$, $\mathrm{p}=0.15 ;$ M. lactis: $\mathrm{z}=-1.02, \mathrm{p}=0.31$; Fig. 1, Exps. 2, 3), indicating an ability of the mosquitoes to discern among different microbes or their metabolites.

\section{Dose of microbes tested}

We grew L. thermotolerans, M. luteus and M. lactis in the synthetic nectar broth for $48 \mathrm{~h}$ and these reached final mean concentrations of $3.85 \times 10^{7}$ cells $/ \mathrm{mL}(\mathrm{N}=2)$, $1.13 \times 10^{5}$ cells $/ \mathrm{mL} \quad(\mathrm{N}=2)$, and $2.85 \times 10^{6}$ cells $/ \mathrm{mL}$ $(\mathrm{N}=2)$, respectively.

H2: The attractiveness of microbes is dependent upon their growth medium

Table 2 Biochemical tests for the identification of microbes collected from the inflorescences of common tansy, Tanacetum vulgare

\begin{tabular}{|c|c|c|c|c|c|c|}
\hline Test & YPD-T2E1 & LB-T1D1-a (round) & $\begin{array}{l}\text { LB-T1D1-b } \\
\text { (filamentous) }\end{array}$ & LB-T4B1 & LB-T1E2 & LB-T4C1 \\
\hline \multicolumn{7}{|l|}{ Fermentation of: } \\
\hline Sucrose & + & + & + & + & Not tested & Not tested \\
\hline Starch & + & + & + & + & Not tested & Not tested \\
\hline L-alanine & - & - & - & - & Not tested & Not tested \\
\hline Glucose & + & + & + & + & Not tested & Not tested \\
\hline Mannitol & - & + & + & + & Not tested & Not tested \\
\hline Xylose & - & - & - & - & Not tested & Not tested \\
\hline Galactose & + & - & - & + & Not tested & Not tested \\
\hline Lactose & - & + & + & Varies & Not tested & Not tested \\
\hline Fructose & + & + & + & + & Not tested & Not tested \\
\hline \multicolumn{7}{|l|}{ Enzyme production: } \\
\hline Catalase test & + & + & + & + & Not tested & Not tested \\
\hline Oxidase test & Not tested & - & - & Varies & Not tested & Not tested \\
\hline Other tests: & & & & & Not tested & Not tested \\
\hline $7 \% \mathrm{NaCl}$ development & Not tested & + & + & - & - & Not tested \\
\hline $10 \% \mathrm{NaCl}$ development & Not tested & + & + & - & Not tested & Not tested \\
\hline Nitrate reduction & Not tested & Not tested & Not tested & Not tested & + & + \\
\hline Hydrolysis of casein & Not tested & Not tested & Not tested & Not tested & + & Not tested \\
\hline Hydrolysis of tween80 & Not tested & Not tested & Not tested & Not tested & Not tested & - \\
\hline Assimilation of L-arabinose & Not tested & Not tested & Not tested & Not tested & - & Not tested \\
\hline Assimilation of D-glucose & Not tested & Not tested & Not tested & Not tested & - & Not tested \\
\hline $10^{\circ} \mathrm{C}$ development & Not tested & Not tested & Not tested & Not tested & + & - \\
\hline $42^{\circ} \mathrm{C}$ development & Not tested & Not tested & Not tested & Not tested & - & Not testec \\
\hline $50^{\circ} \mathrm{C}$ development & Not tested & - & + & - & Not tested & Not tested \\
\hline $\mathrm{KOH}$ string test & Not relevant & Gram + & Gram+ & Gram + & Not tested & Not tested \\
\hline
\end{tabular}




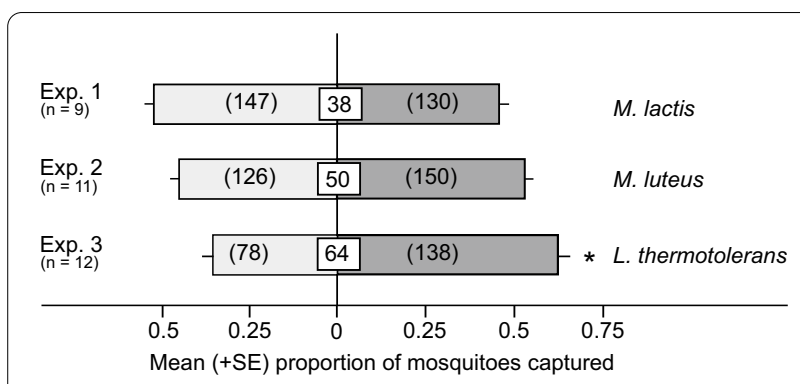

Fig. 1 Mean proportion of Culex pipiens females captured in paired traps baited with a synthetic nectar broth inoculated, or not (control; light grey bars), with Micrococcus lactis (Exp. 1), Micrococcus luteus (Exp. 2), or Lachancea thermotolerans (Exp. 3). Numbers in white boxes represent the mean percentage of non-responding mosquitoes, and numbers within parentheses the total number of mosquitoes captured. The asterisk (*) in Exp. 3 indicates a significant preference for the treatment stimulus (binary logistic regression with a logit link function, $\mathrm{P}<0.05$ )

To determine whether the attractiveness of $L$. thermotolerans is affected by its nutrient source, single colonies of $L$. thermotolerans were spread-plated onto

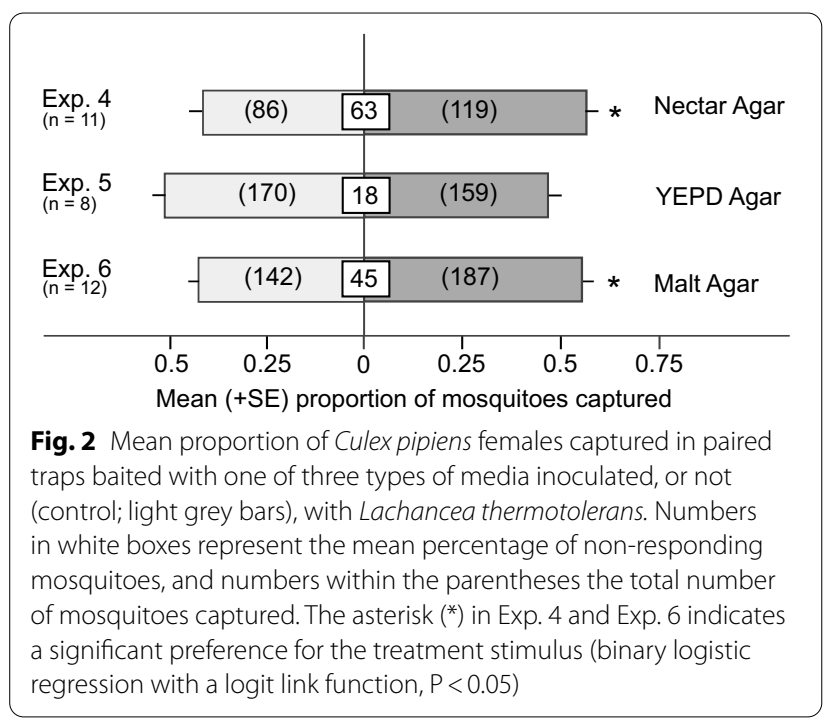

synthetic nectar agar, malt extract agar or YEPD agar plates. In two-choice laboratory experiments, we then tested attraction of $C x$. pipiens to paired traps baited with either one of the three types of inoculated agar (each with $40-60 \%$ microbial growth coverage) or an uninoculated control agar. Lachancea thermotolerans growing on synthetic nectar agar (Exp. 4) or malt extract agar (Exp. 5) attracted more female $C x$. pipiens than corresponding agar controls but not when growing on YEPD agar (Exp. 6) (Exp. 4: $\mathrm{z}=2.29, \mathrm{p}=0.02$; Exp. 5: $\mathrm{z}=2.47, \mathrm{p}=0.013$; Exp. 6: $\mathrm{z}=-0.61, \mathrm{p}=0.54$; Fig. 2). Thus, attraction of $C x$. pipiens females to L. thermotolerans is contingent upon the nutrients available to this yeast.

H3: Multiple species of nectar-colonizing microbes attract more mosquitoes than single microbe species

We hypothesized that odorants from different microbes may have additive or synergistic effects on attraction of $C x$. pipiens females; therefore, we investigated whether $M$. lactis, M. luteus and $L$. thermotolerans presented together are more attractive than each microbe on its own. We inoculated synthetic nectar in separate petri dishes with single colonies of M. lactis, M. luteus or L. thermotolerans, and in laboratory experiments tested attraction of female $C x$. pipiens to paired traps baited with each species alone or in ternary combination. Surprisingly, the ternary combination was as attractive as $M$. lactis alone $(\mathrm{z}=-1.08, \mathrm{p}=0.28$; Fig. 3, Exp. 7) and $M$. luteus alone ( $\mathrm{z}=-0.33, \mathrm{p}=0.74$; Fig. 3, Exp. 8), and even less attractive than $L$. thermotolerans alone $(\mathrm{z}=1.96$, $\mathrm{p}=0.05$; Fig. 3, Exp. 9). Hence, the attractiveness of $L$. thermotolerans was actually reduced when it was presented alongside the two bacterial species.

\section{Identification of microbe-derived volatiles}

We used dynamic headspace aerations to capture the odorants emitted from $L$. thermotolerans and identified them by gas chromatography-mass spectrometry (GCMS). In response to the nutrients provided by the three types of media, L. thermotolerans produced different odor blends (Fig. 4). The yeast grown on all three media generated 2-phenylethanol, and dimethyl trisulfide was detected in two media types. All microbe-produced compounds differed from those originating from the media themselves (Table 3).

\section{$\mathrm{CO}_{2}$ production from synthetic nectar}

Over the course of $150 \mathrm{~h}$, L. thermotolerans growing in synthetic nectar broth sealed with a $98 \%$ sulfuric acid vapour lock produced $343 \mathrm{mg}$ of $\mathrm{CO}_{2}$ (Fig. 5).

\section{Discussion}

Our data show that diverse microbes including the yeast Lachancea thermotolerans colonize floral nectar of tansy. Lachancea thermotolerans growing on synthetic nectar or malt extract media produce odorants that attract female Culex pipiens. Furthermore, we show that $L$. thermotolerans grown in a synthetic nectar broth produces $\mathrm{CO}_{2}$ and that $L$. thermotolerans alone is more attractive to female $C x$. pipiens than when presented along with two bacteria also isolated from the same inflorescences. Below we elaborate on our conclusions.

Our culture-based approach to isolate nectar-colonizing microbes from common tansy likely under-represents 


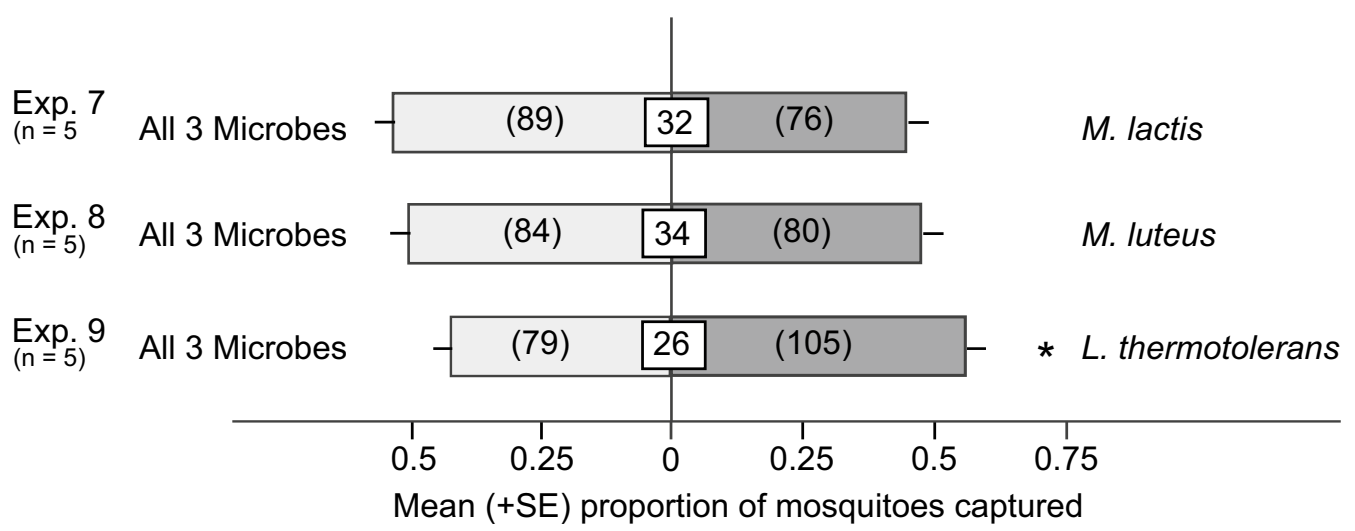

Fig. 3 Mean proportion of Culex pipiens females captured in paired traps baited with one or three vessels containing synthetic nectar broth, each inoculated with one of three microbes: Micrococcus lactis, M. luteus and Lachancea thermotolerans. Numbers in white boxes represent the mean percentage of non-responding mosquitoes, and numbers within parentheses the total number of mosquitoes captured. The asterisk (*) in Exp. 9 indicates a significant preference for the $L$. thermotolerans test stimulus (binary logistic regression with a logit link function, $P<0.05$ )

the microbial diversity present in nectaries [49]; nevertheless, our collection of 19 isolates representing at least 12 species of microbes compares favourably with results of other studies examining microbial diversity in floral nectar using culture methods [6-8]. We isolated Staphylococcus epidermidis which may have been a contaminant because this microbe is typically associated with human skin. However, other microbes, such as Candida albicans [50] (not isolated in our study) which are thought to be obligate commensals of animals, have also been isolated from the environment [51]. Although culture-independent methods such as metagenomic analysis can be used to examine microbial diversity without the selection pressures of culturing, only by obtaining live cultures of the colonizing microbes could we study the odor profiles of these isolates and test their ability to attract $C x$. pipiens.

Microbe-derived semiochemicals have been shown to guide foraging behavior of mosquitoes in a variety of contexts. Semiochemicals emitted from human skin microbiota, including S. epidermidis, Corynebacterium minutissimum and Brevibacterium epidermidis, attract mosquitoes to human hosts [39, 41, 52, 53]. Moreover, semiochemicals from Psychrobacter immobilis, Sphingobacterium multivorum, Bacillus spp., Pseudomonas spp., Klebsiella spp., and others help mosquitoes locate suitable oviposition sites [44, 46]. Finally, semiochemicals emitted from microbes colonizing aphid honeydew [38], or present in floral nectar [this study], attract sugar-foraging mosquitoes.

Microbes could also inform mosquitoes about the prospect of obtaining a sugar meal. The odor profiles of inflorescences differ not only between plant species [54] but also within the same species due, in part, to microbe-specific odorants [17]. These odorants may enable mosquitoes to discern inflorescences with sugarrich and sugar-poor rewards, analogous to mosquitoes selecting human hosts based, in part, on their skin microbiota [40, 41]. Emission of microbe-semiochemicals from nectaries could inform mosquitoes about the presence of nectar-dwelling microbes which, in turn, would signal sugar or amino acid metabolism and thus the availability of sugar or amino acids. Alternatively, microbe odorants could indicate microbe presence stemming from a previous insect floral visit that may have temporarily depleted the sugar resource. Mosquitoes themselves are capable of microbe phoresis, as shown with floral nectar surrogates [55], as are many other insects visiting inflorescences or obtaining floral nectar $[56,57]$.

The informative value of microbe-derived odorants to foraging mosquitoes became evident when we grew L. thermotolerans in/on different nutrient sources. The nutrients available to $L$. thermotolerans not only affected the odorants it produced (Fig. 4) but also their attractiveness to foraging mosquitoes. This implies that the presence and composition of specific microbial odorants could inform mosquitoes about the availability of particular nutrients such as carbohydrates and amino acids. Lachancea thermotolerans grown in synthetic nectar broth produced appreciable amounts of $\mathrm{CO}_{2}$ whichwhile only weakly attractive on its own [42] - synergistically enhances the attractiveness of floral and host semiochemicals to both nectar- and host-foraging mosquitoes [38, 42].

Lachancea thermotolerans and its odor bouquet, respectively, also attract several species of North American yellowjackets (Hymenoptera: Vespidae) $[58,59]$ and the green lacewing, Chrysoperla comanche (Stephens) [60]. When grown and aerated on grape juice agar, $L$. 


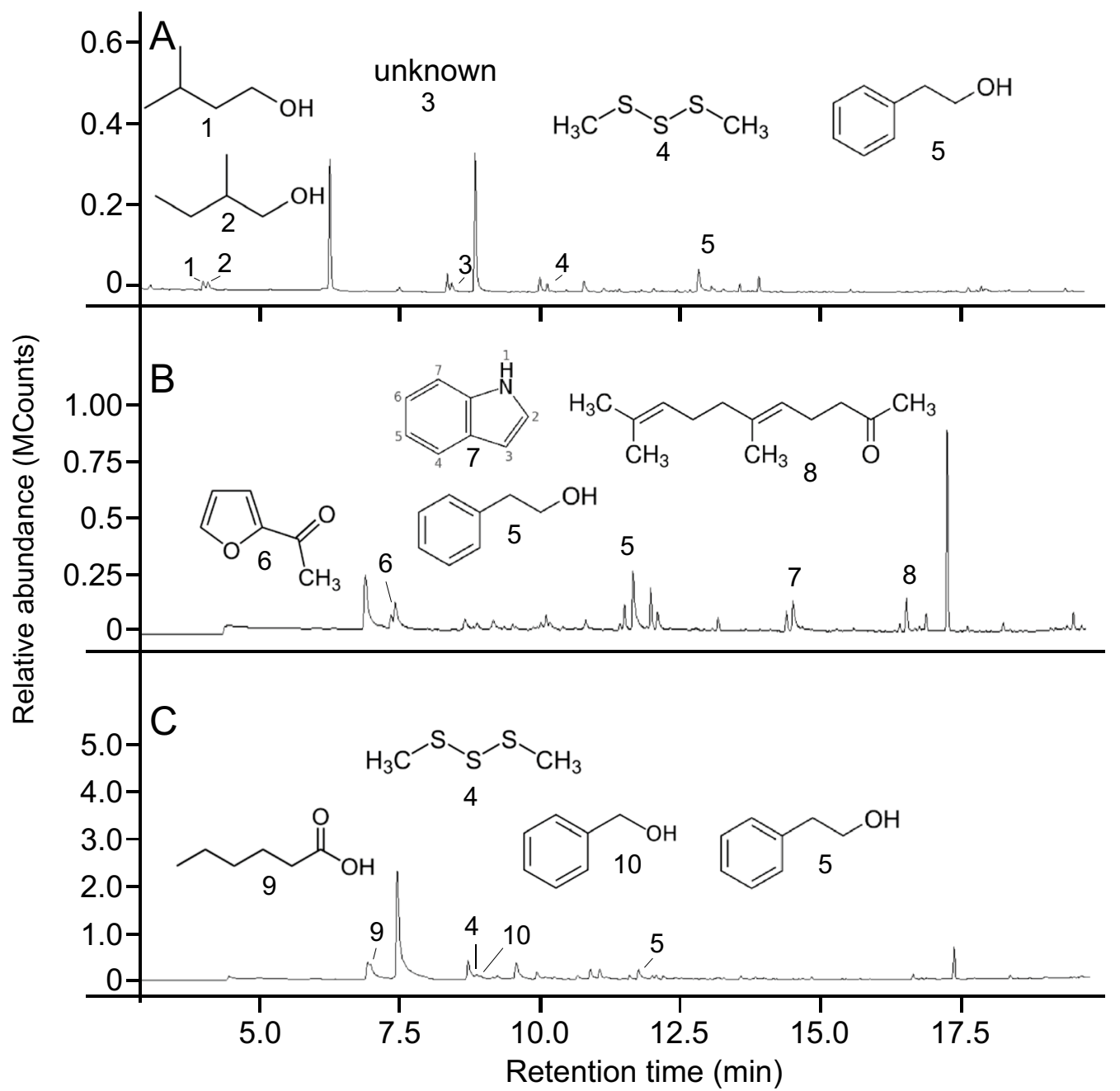

Fig. 4 Headspace odorants from plates of YEPD agar (a), malt extract agar (b), and synthetic nectar agar plates (c) that were inoculated with Lachancea thermotolerans and that were not present in the headspace of uninoculated control plates. Compounds produced by L. thermotolerans were 3-methyl-butanol (1); 2-methyl-butanol (2); unknown (3); dimethyl trisulfide (4); 2-phenylethanol (5); 2-acetyl furan (6); indole (7); geranyl acetone (8); hexanoic acid (9) and benzyl alcohol (10). Note: different retention times of the same compounds in panels A-C are due to different temperature programs run during gas chromatographic analyses (see "Methods" for details)

thermotolerans produced 20 odorants which, when fieldtested as a synthetic blend, attracted Western yellowjackets, Vespula pensylvanica [58]. Two of the odorants in this blend, 2-phentylethanol and 2-acetylfuran, were also found in this study. Lachancea thermotolerans is frequently isolated from fruit or fruit-related resources [61, $62]$ and is used in wine fermentations to generate ethanol and lactic acid [63].

Most studies investigating relationships between nectar-dwelling microbes and floral visitation by insects have focussed on hymenopterans (but see [64]), yet dipterans are also frequent visitors and important pollinators of flowers [65-68], and they interact with microbes $[3,69]$. Our results suggest microbe-mediated, or at least modulated, inflorescence visitation by mosquitoes. This concept has been suggested for some hymenopteran pollinators including the European honey bee, Apis mellifera [13], and several species of bumble bees, Bombus spp. $[17,18]$, that preferentially visit inflorescences with nectar-dwelling yeasts, primarily Metschnikowia reukaufii. Conversely, both honey bees and bumble bees avoid inflorescences with certain nectar-dwelling bacteria [19, 20]. The combined information indicates that microbes can alter the floral scent [15], thereby prompting attraction or avoidance of specific floral visitors.

In follow-up studies, the sample size, while adequate, could be increased and the complete visitation 
Table 3 Headspace odorants of YEPD agar, malt extract agar and synthetic nectar agar, each inoculated with Lachancea thermotolerans. Compounds in bold font were found in two or more samples

\begin{tabular}{ll}
\hline Medium & Compounds $^{\mathbf{a}}$ \\
\hline YEPD agar & 2-Methyl-1-butanol \\
& 3-Methyl-1-butanol \\
& 2-Phenylethanol \\
Dimethyl trisulfide \\
Malt extract agar & 2-Acetylfuran \\
& 2-Phenylethanol \\
& Indole \\
Synthetic nectar agar & Geranyl acetone \\
& Hexanoic acid \\
& Dimethyl trisulfide \\
& Benzyl alcohol \\
& 2-Phenylethanol
\end{tabular}

a All compounds were absent from the headspace of corresponding uninoculated control agar

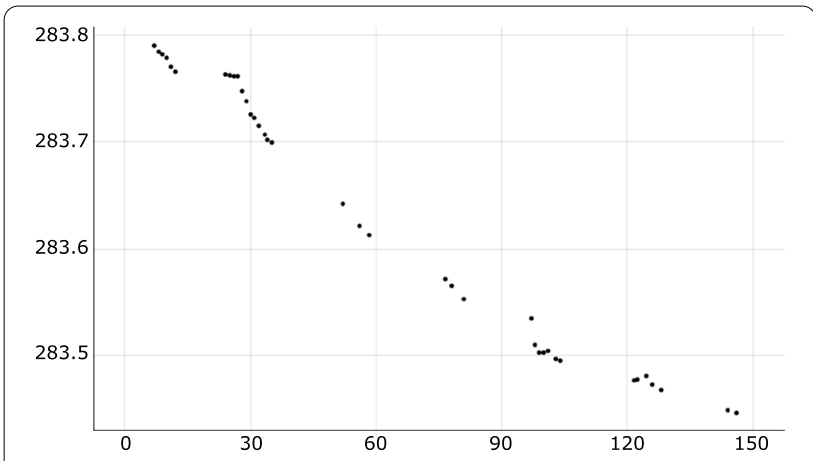

Fig. 5 Weight loss over time of synthetic nectar broth $(25 \mathrm{~mL})$ inoculated with Lachancea thermotolerans due to fermentation and $\mathrm{CO}_{2}$ emission by L. thermotolerans

history of plants could be tracked, thereby revealing the insect vectors of any microbe inoculum. Moreover, to determine the amount of inoculum and the resulting odor intensity needed to attract mosquitoes, a dose-response experiment could be run with one test stimulus reflecting the odor intensity of a representative tansy inflorescence. We tested $10 \mathrm{ml}$ of synthetic nectar in our laboratory bioassays. This took into account that (i) each common tansy possesses multiple inflorescences, (ii) each inflorescence comprises dozens of composite flowers, and (iii) each composite flower contains up to 300 florets, each of which can produce up to $\sim 1 \mu \mathrm{L}$ of nectar (D. P. Pers. Obs.). Therefore, the volume of synthetic nectar we bioassayed approximates the volume of nectar produced by a common tansy or a group of common tansies. Similarly, the amount of synthetic nectar odorants we assayed resembled that of odorants produced by nectar-dwelling microbes and which would be encountered by foraging mosquitoes in field settings.

\section{Conclusion}

We demonstrate that floral nectar of common tansies contains various microbes, and we identified 19 to genus level or further. Of the three species tested in behavioral bioassays, only the yeast $L$. thermotolerans had a significant effect on the attraction of female $C x$. pipiens, which was diminished, rather than improved, by admixture with two bacterial species. The attractiveness of $L$. thermotolerans to $C x$. pipiens females was dependent upon its nutrient source and linked to a distinct odorant profile, although a causal relationship was not tested. We propose that specific components of the odor blend signal the availability of certain macro-nutrients such as sugar and amino acids which, in turn, inform foraging decisions by mosquitoes. It would now be interesting to determine the key odorant(s) in the microbe odorant blend that mediate(s) the attraction of mosquitoes.

\section{Methods \\ Microbe collection}

We collected $40 \mathrm{~T}$. vulgare florets, from 20 inflorescences (2 florets per inflorescence), from 4 plants (5 inflorescences per plant) during September, 2017, in Delta, BC (Canada), wearing latex gloves (VWR International, Radnor, USA) and a surgical mask (Acklands Ltd., Wawa, Canada). All plants were collected within a $3-\mathrm{m}^{2}$ patch of tansy beside a secondary road in a rural farming area. Immediately prior to sample collections, DP observed an adult female mosquito (likely Aedes dorsalis) visiting this tansy patch. We immediately placed inflorescences into sterile Ziploc bags (S.C. Johnson, Racine, USA) and stored them on ice for transport to the lab. Using ethanol and flame-sterilized scissors, we removed the tops of florets and inserted an autoclaved glass micro-capillary, prepared with a micropipette puller (Model P-1000, Sutter Instrument Co., Novato, USA), into the nectary to draw nectar via capillary action. Each draw yielded a maximum of $\sim 1 \mu \mathrm{L}$ of nectar. We repeated this twice on the same composite flower, using only one composite flower per inflorescence. We then inserted, and subsequently shattered, the micro-capillary into a sterile microcentrifuge tube $(1.5 \mathrm{~mL}$; ThermoFisher Scientific Inc., Waltham, USA) containing autoclaved distilled water $(400 \mu \mathrm{L})$. We pipetted a $100-\mu \mathrm{L}$ aliquot of this solution onto yeast extract peptone dextrose agar (YEPD) plates $(20 \mathrm{~g} / \mathrm{L}$ bacteriological peptone, $10 \mathrm{~g} / \mathrm{L}$ yeast extract, $20 \mathrm{~g} / \mathrm{L}$ glucose, 
15 g/L agar) (Sigma Aldrich, St. Louis, USA) and LuriaBertani agar (LB) plates $(10 \mathrm{~g} / \mathrm{L}$ tryptone, $5 \mathrm{~g} / \mathrm{L}$ yeast extract, $5 \mathrm{~g} / \mathrm{L} \mathrm{NaCl}, 15 \mathrm{~g} / \mathrm{L}$ agar) (Sigma Aldrich, St. Louis, USA), spread it with a sterile glass rod, and then incubated plates for $48-72 \mathrm{~h}$ at $30{ }^{\circ} \mathrm{C}$. We subsequently re-streaked morphologically distinct colonies onto new plates to obtain pure colonies. Working cultures were maintained at $4{ }^{\circ} \mathrm{C}$. Storage cultures of each isolate were prepared with $20 \%$ glycerol and stored at $-80^{\circ} \mathrm{C}$.

\section{Microbe identification}

Cells from a single colony were picked and grown in liquid YEPD or LB media for $24 \mathrm{~h}$ at $30{ }^{\circ} \mathrm{C}$, and DNA was extracted according to Rose et al. 1990 [70]. DNA concentrations were estimated using a NanoDrop UV/Vis 2000 spectrophotometer (ThermoFisher Scientific Inc., Waltham, USA). To identify bacteria, we used Taq DNA polymerase (Applied Biological Materials, Richmond, Canada) to amplify the V3-V4 loop of the 16S rDNA gene with the Universal Forward Primer (UniF) - $5^{\prime}$-CCT ACGGGRBGCASCAG-3' and the Universal Reverse Primer (UniR)-5'-GGACTACNNGGGTATCTAAT$3^{\prime}$ [71], and to amplify the 26S rDNA gene of yeast, we used the NL1 primer-5'-GCATATCAATAAGCGGAG GAAAAG-3'-and NL4 primer-5'-GGTCCGTGTTTC AAGACGG-3' [72]. The identity of the colony found to be $L$. thermotolerans was confirmed using the specific primers INT2F (5'-TGGTTTTATTGAAGCCAAAGG$3^{\prime}$ ) and INT2R (5'-GGGGACCCGGAGATTAATAG-3') [73]. PCR amplicons were pooled and concentrated using the NucleoSpin Gel and PCR Clean-up kit (Machery-Nagel, Duren, Germany). We sequenced amplicons (Genewiz, South Plainfield, USA) and used the Basic Local Alignment Search Tool (BLAST) [74] to compare the sequenced region of individual isolates with known sequences. A species or genus was determined to be a match if there was at least 95\% coverage and 99\% identity using BLAST with the sequenced isolate. In addition, we ran biochemical and physiological tests on select isolates (see Table 1) and Gram-tested bacterial colonies on select plates using $\mathrm{KOH}$ (Table 2). Biochemical tests were carried out according to established procedures $[75,76]$. We determined the ability of isolates to grow at $7 \% \mathrm{NaCl}$ and $10 \% \mathrm{NaCl}$ in liquid media, and we tested isolate growth at various temperatures. For unknown Bacillus and Epidermidis isolates, catalase and oxidase enzyme production tests as well as sucrose, starch, L-alanine, glucose, mannitol, galactose, lactose, and fructose fermentation tests were run. For Micrococcus isolates, nitrate reduction, hydrolysis, and assimilation tests were run. We identified test isolates by comparing biochemical test results with data from the bioMérieux api ${ }^{\circledR} 50 \mathrm{CHB} / \mathrm{E}$ test kit (bioMérieux SA, Lyon, France) and reference papers [77-81].

\section{Rearing of experimental mosquitoes}

We reared Cx. pipiens at $23-26{ }^{\circ} \mathrm{C}, 40-60 \% \mathrm{RH}$, and a photoperiod of 14L:10D. We kept mixed groups of males and females in mesh cages $(30 \times 30 \times 46 \mathrm{~cm}$ high $)$ and provisioned them with a $10-\%$ sucrose solution ad libitum. The primary author (DP) blood-fed females once per week. For oviposition, gravid females were given access to water in circular glass dishes $(10 \mathrm{~cm}$ diameter $\times 5 \mathrm{~cm}$ high). We transferred eggs to water-filled trays $(45 \times 25 \times 7 \mathrm{~cm}$ high $)$ and sustained larvae with NutriFin Basix tropical fish food (Rolf C. Hagen Inc., Baie-D'Urfe, Canada). We transferred pupae via a $7-\mathrm{mL}$ plastic pipette (VWR International, Radnor, USA) to water-containing 354-mL Solo cups covered with a mesh lid. Using an aspirator, we collected emergent adults and placed them in similar cups, along with a cotton ball soaked in a $10-\%$ sucrose solution.

\section{Behavioural bioassays}

We ran all behavioral bioassays in mesh cages $(77 \times 78 \times 104 \mathrm{~cm})$ which were wrapped in black fabric except for the top, thereby allowing ambient fluorescent light illumination. During bioassays, we kept cages at $23-26{ }^{\circ} \mathrm{C}, 40-60 \% \mathrm{RH}$ and a photoperiod of $14 \mathrm{~L}: 10 \mathrm{D}$. For each 24-h bioassay, we released 50 virgin $C x$. pipiens females, 1- to 3-day-old, 24-h sugar-deprived into a cage fitted with adhesive-coated (The Tanglefoot Comp., Grand Rapids, USA) paired delta traps $(9 \mathrm{~cm} \times 15 \mathrm{~cm})$ on burette stands spaced $30 \mathrm{~cm}$ apart. For each bioassay which ran for about $24 \mathrm{~h}$, treatment and control stimuli were randomly assigned to these traps. At the end of each bioassay the number of mosquitoes in each trap was counted.

\section{Growth conditions for nectar-derived microorganisms}

We grew microbes on YEPD agar plates, malt extract agar plates $(3 \% \mathrm{w} / \mathrm{v}$ malt extract, $0.2 \% \mathrm{w} / \mathrm{v}$ peptone, $1.5 \%$ $\mathrm{w} / \mathrm{v}$ agar), and synthetic nectar agar or nectar broth $(10 \%$ $\mathrm{w} / \mathrm{v}$ sucrose, $2 \% \mathrm{w} / \mathrm{v}$ yeast extract). All agar plates were 92-mm diam Petri dishes (Sarstedt Inc., Nümbrecht, Germany). The synthetic nectar broth was prepared in an autoclaved 2-L Erlenmeyer flask. After streaking single colonies onto plates or inoculating broth, we incubated cultures for approximately $48-72 \mathrm{~h}$ at $23-26{ }^{\circ} \mathrm{C}$ and $40-60 \% \mathrm{RH}$. We used plates with microbial growth covering $40-60 \%$ of the surface area for behavioural bioassays.

\section{Attractiveness of microbes in synthetic nectar}

In two-choice laboratory experiments with a pairedtrap design, we tested attraction of female $C x$. pipiens to microbe-derived odorants. We pipetted $10 \mathrm{~mL}$ of the treatment stimulus [synthetic nectar broth inoculated 
with L. thermotolerans, M. lactis or M. luteus and incubated as described above] into a sterile $92-\mathrm{mm}$ diam Petri dish which we placed into a randomly assigned delta trap. The paired control stimulus consisted of a sterile synthetic nectar broth $(10 \mathrm{~mL})$ presented the same way. We bioassayed the response of female $C x$. pipiens as described above in "behavioural bioassays".

\section{Attractiveness of $L$. thermotolerans growing on different media}

In two-choice laboratory experiments with a paired-trap design, we tested attraction of female $C x$. pipiens to $L$. thermotolerans with $40-60 \%$ surface area coverage cultured on YEPD agar, malt extract agar, or synthetic nectar agar prepared as described above. In each bioassay, the corresponding uninoculated agar media served as the paired control stimulus.

\section{Comparative attractiveness of single- vs multiple-species of microbes}

In two-choice laboratory experiments with paired traps, we compared attraction of female $C x$. pipiens to $L$. thermotolerans, M. lactis, and M. luteus presented singly or in ternary combination in the same trap. We cultured each microbe separately in synthetic nectar broth as described above, and pipetted $3.3 \mathrm{~mL}$ of each broth into a separate sterile 35-mm Petri dish (Sarstedt Inc., Nümbrecht, Germany). As a result, paired traps were baited with either one or three Petri dishes in each bioassay, the design of which is as described in the "Behavioural bioassay" section.

\section{Dose of microbes tested}

We determined the concentration of microbes used in experiments by performing serial dilutions of microbeinoculated synthetic nectar broth after incubation at $25{ }^{\circ} \mathrm{C}$ for $48 \mathrm{~h}$. Cell density was determined using a hemacytometer.

\section{Measurement of $\mathrm{CO}_{2}$ production by L. thermotolerans}

We inoculated sterile synthetic nectar broth $(25 \mathrm{~mL})$ with a single colony-forming unit of L. thermotolerans previously grown on YEPD agar, and then incubated the broth at $30{ }^{\circ} \mathrm{C}$ for 5 days. We added an aliquot $(10 \mu \mathrm{L})$ of this broth to $100 \mathrm{~mL}$ of sterile synthetic nectar broth in a 250-mL Erlenmeyer flask, attached a vapour lock ( $5 \mathrm{~mL}$ of $98 \%$ sulfuric acid) to maintain vapour pressure and prevent water loss, and obtained the starting weight. We incubated the entire assembly in a water bath kept at $30{ }^{\circ} \mathrm{C}$ in the fume hood and monitored weight loss as a proxy for $\mathrm{CO}_{2}$ emission [82].

\section{Dynamic headspace odorant collections}

We placed 12 plates with $L$. thermotolerans grown for $48-72 \mathrm{~h}$ at $23-26{ }^{\circ} \mathrm{C}$ on YEPD, malt agar, or SN media into a Pyre ${ }^{\circledR}$ glass chamber $(34 \mathrm{~cm}$ high $\times 12.5 \mathrm{~cm}$ wide). A mechanical pump drew charcoal-filtered air at a flow of $1 \mathrm{~L} \mathrm{~min}^{-1}$ for $24-72 \mathrm{~h}$ through the chamber and through a glass column $(6 \mathrm{~mm}$ outer diameter $\times 150 \mathrm{~mm})$ containing $200 \mathrm{mg}$ of Porapak- $\mathrm{Q}^{\mathrm{TM}}$ adsorbent. We desorbed odorants captured on Porapak with $0.5 \mathrm{~mL}$ each of pentane and ether. We analyzed 2- $\mu$ l aliquots of Porapak$\mathrm{Q}^{\mathrm{TM}}$ extract by gas chromatography-mass spectrometry (GC-MS), operating a Saturn 2000 Ion Trap GC-MS fitted with a DB-5 GC-MS column $(30 \mathrm{~m} \times 0.25 \mathrm{~mm}$ i.d.; Agilent Technologies Inc., Santa Clara, USA) in full-scan electron impact mode. To chromatograph the odorants of $L$. thermotolerans on malt extract agar and on synthetic nectar agar, we used a flow of helium $\left(35 \mathrm{~cm} \mathrm{~s}^{-1}\right)$ as the carrier gas with the following temperature program: $50{ }^{\circ} \mathrm{C}$ (5 min), $10{ }^{\circ} \mathrm{C} \mathrm{min}^{-1}$ to $280{ }^{\circ} \mathrm{C}$ (held for $10 \mathrm{~min}$ ). The temperature of the injector port was $250{ }^{\circ} \mathrm{C}$ and the ion trap was set to $200{ }^{\circ} \mathrm{C}$. To analyze the odorants of $L$. thermotolerans on YEPD agar, and to reveal very volatile compounds that may have eluded detection using the above temperature program, we retained the same helium flow $\left(35 \mathrm{~cm} \mathrm{~s}^{-1}\right)$ but lowered the initial temperature, running the following temperature program: $40{ }^{\circ} \mathrm{C}$ (5 min), $10{ }^{\circ} \mathrm{C} \mathrm{min}^{-1}$ to $280^{\circ} \mathrm{C}$ (held for $10 \mathrm{~min}$ ). Aliquots of headspace odorant extracts were injected in split mode with a 1:1 split ratio, and the temperature of the injector port and the ion trap were set to $250{ }^{\circ} \mathrm{C}$ and $200{ }^{\circ} \mathrm{C}$, respectively. We identified odorants in headspace odorant extracts by comparing their retention indices (RI; relative to $n$-alkane standards) [83] and their mass spectra with those reported in the literature and with those of authentic standards.

\section{Statistical analyses}

We used SAS software version 9.4 (SAS Institute Inc., Cary, USA) to analyze data, excluding from analyses all experimental replicates with no mosquitoes captured in traps. We used a binary logistic regression model with a logit link function to compare mean proportions of responders between test stimuli, and used back-transformed data to attain means and confidence intervals.

\section{Abbreviations \\ GC-MS: Gas chromatography-mass spectrometry; LB: Luria-Bertani medium; PCR: Polymerase chain reaction; $\mathrm{RH}$ : Relative humidity; Rl: Retention index; YEPD: Yeast extract peptone dextrose medium.}

Acknowledgements

We thank Martin Duckhorn for his volunteer assistance in the project. 


\begin{abstract}
Authors' contributions
$\mathrm{DP}, \mathrm{GG}, \mathrm{MM}$, and $\mathrm{CL}$ designed the study. DP collected the microbe samples. DP, CC, HC, NY, SG, SM, AB, and EG identified the microbes. RG identified the microbial odorants. DP, EG, SM, and YU ran the bioassays. DP, EG, and YU analyzed data statistically. DP and GG wrote the manuscript. All authors read and approved the final manuscript.
\end{abstract}

\section{Funding}

The research was supported by scholarships to DP (Natural Sciences and Engineering Research Council of Canada [NSERC; https://www.canada.ca/en/scien ce-engineering-research.html] PGSD; SFU Provost's Prize of Distinction [https ://www.sfu.ca/dean-gradstudies/awards/entrance-scholarships/provost-award s/ppd.html]; John H Borden Scholarship [http://esc-sec.ca/student/stude nt-awards/\#toggle-id-5]), scholarships to NY and EG (NSERC — Undergraduate Student Research Award), and by an NSERC —-Industrial Research Chair to GG, with Scotts Canada Ltd. as the industrial sponsor. These funding bodies had no role in the design of the study, the collection, analysis, and interpretation of data, nor writing of this manuscript.

\section{Availability of data and materials}

The datasets generated and or analysed during the current study are available in the Dryad repository [https://doi.org/10.5061/dryad.j6q573ncw], and the genetic sequences are available from the National Center for Biotechnology Information GenBank [https://www.ncbi.nlm.nih.gov/genbank] (see Table 1 for accession numbers).

\section{Ethics approval and consent to participate}

Not applicable.

\section{Consent for publication}

Not applicable.

\section{Competing interests}

The authors declare that their industrial sponsor, Scotts Canada Ltd., had no role in the study design, data collection, analysis, and interpretation, drafting the paper, or the decision to submit the manuscript for publication. The authors also declare that their relationship with Scotts Canada Ltd. does not alter their adherence to BMC policies on data and material sharing. The authors further declare that they have no financial or non-financial competing interests.

\footnotetext{
Author details

1 Simon Fraser University, 8888 University Drive, Burnaby, BC, Canada. ${ }^{2}$ The University of British Columbia, 2329 West Mall, Vancouver, BC, Canada.

${ }^{3}$ University of Saskatchewan, 129-72 Campus Drive, Saskatoon, SK, Canada.

${ }^{4}$ Emerging Pathogens Institute, University of Florida, 2055 Mowry Road, Gainesville, FL, USA.
}

Received: 16 December 2020 Accepted: 8 February 2021 Published online: 16 February 2021

\section{References}

1. Douglas AE. Multiorganismal insects: diversity and function of resident microorganisms. Annu Rev Entomol. 2015;60:17-34.

2. Davis TS, Crippen TL, Hofstetter RW, Tomberlin JK. Microbial volatile emissions as insect semiochemicals. J Chem Ecol. 2013;39:840-59.

3. Uriel Y, Gries R, Tu L, Carroll C, Zhai H, Moore M, et al. The fly factor phenomenon is mediated by inter-kingdom signalling between bacterial symbionts and their blow fly hosts. Insect Sci. 2020;27:256-65.

4. Knudsen JT, Eriksson R, Gershenzon J, Ståhl B. Diversity and distribution of floral scent. Bot Rev. 2006;72:1-120.

5. Herrera CM, Pozo MI. Nectar yeasts warm the flowers of a winter-blooming plant. Proc R Soc B Biol Sci. 2010;277:1827-34.

6. Pozo Ml, Herrera CM, Bazaga P. Species richness of yeast communities in floral nectar of southern Spanish plants. Microb Ecol. 2011;61:82-91.

7. Fridman S, Izhaki I, Gerchman Y, Halpern M. Bacterial communities in floral nectar. Environ Microbiol Rep. 2012;4:97-104.
8. Álvarez-Pérez S, Herrera CM, de Vega C. Zooming-in on floral nectar: a first exploration of nectar-associated bacteria in wild plant communities. FEMS Microbiol Ecol. 2012;80:591-602

9. Herrera CM, de Vega C, Canto A, Pozo MI. Yeasts in floral nectar: a quantitative survey. Ann Bot. 2009;103:1415-23.

10. Canto A, Herrera CM. Micro-organisms behind the pollination scenes: microbial imprint on floral nectar sugar variation in a tropical plant community. Ann Bot. 2012;110:1173-83.

11. Herrera CM, García IM, Pérez R. Invisible floral larcenies: Microbial communities degrade floral nectar of bumble bee-pollinated plants. Ecology. 2008;89:2369-76

12. Canto A, Herrera CM, Medrano M, Pérez R, Garcia IM. Pollinator foraging modifies nectar sugar composition in Hellebrous foetidus (Ranunculaceae): an experimental test. Am J Bot. 2008;95:315-20.

13. Rering CC, Beck JJ, Hall GW, McCartney MM, Vannette RL. Nectar-inhabiting microorganisms influence nectar volatile composition and attractiveness to a generalist pollinator. New Phytol. 2018;220:750-9.

14. Schaeffer RN, Irwin RE. Yeasts in nectar enhance male fitness in a montane perennial herb. Ecology. 2014;95:1792-8.

15. Golonka AM, Johnson BO, Freeman J, Hinson DW. Impact of nectarivorous yeasts on Silene caroliniana's scent. East Biol. 2014;3:1-26.

16. Bruce TJA, Wadhams LJ, Woodcock CM. Insect host location: a volatile situation. Trends Plant Sci. 2005;10:269-74.

17. Yang M, Deng G-C, Gong Y-B, Huang S-Q. Nectar yeasts enhance the interaction between Clematis akebioides and its bumblebee pollinator. Plant Biol. 2019;21:732-7.

18. Herrera CM, Pozo Ml, Medrano M. Yeasts in nectar of an early-blooming herb: Sought by bumble bees, detrimental to plant fecundity. Ecology. 2013:94:273-9.

19. Good AP, Gauthier MPL, Vannette RL, Fukami T. Honey bees avoid nectar colonized by three bacterial species, but not by a yeast species, isolated from the bee gut. PLOS ONE. 2014;9:e86494.

20. Junker RR, Romeike T, Keller A, Langen D. Density-dependent negative responses by bumblebees to bacteria isolated from flowers. Apidologie. 2014:45:467-77.

21. Raza W, Wang J, Jousset A, Friman V-P, Mei X, Wang S, et al. Bacterial community richness shifts the balance between volatile organic compoundmediated microbe-pathogen and microbe-plant interactions. Proc R Soc B Biol Sci. 2020;287:20200403.

22. Foster WA. Mosquito sugar feeding and reproductive energetics. Annu Rev Entomol. 1995;40:443-74.

23. Clements A. The sources of energy for flight in mosquitoes. Exp Biol. 1955;32:547-54.

24. Manda H, Gouagna LC, Foster WA, Jackson RR, Beier JC, Githure Jl, et al. Effect of discriminative plant-sugar feeding on the survival and fecundity of Anopheles gambiae. Malar J. 2007;6:1-11.

25. Nayar JK, Sauerman DM. Physiological effects of carbohydrates on survival, metabolism, and flight potential of female Aedes taeniorhynchus. J Insect Physiol. 1971;17:2221-33.

26. Clements $A$. The biology of mosquitoes, volume 2: sensory reception and behaviour. Wallingford: CABI Publishing; 1999.

27. Peach DAH, Gries G. Mosquito phytophagy — sources exploited, ecological function, and evolutionary transition to haematophagy. Entomol Exp Appl. 2020;168:120-36.

28. Peach DAH, Ko E, Blake AJ, Gries G. Ultraviolet inflorescence cues enhance attractiveness of inflorescence odour to Culex pipiens mosquitoes. PLoS ONE. 2019;14:e0217484

29. Peach DAH, Gries R, Zhai H, Young N, Gries G. Multimodal floral cues guide mosquitoes to tansy inflorescences. Sci Rep. 2019;9:3908.

30. Foster WA. Phytochemicals as population sampling lures. J Am Mosq Control Assoc. 2008;24:138-46.

31. Nyasembe $\mathrm{V}$, Torto B. Volatile phytochemicals as mosquito semiochemicals. Phytochem Lett. 2014;8:196-201.

32. Müller GC, Xue R, Schlein Y. Differential attraction of Aedes albopictus in the field to flowers, fruits and honeydew. Acta Trop. 2011;118:45-9.

33. Yu B, Huang $\mathrm{S}$, Ding $Y$, Fouad $\mathrm{H}, \mathrm{Li} \mathrm{H}, \mathrm{Mo} \mathrm{JC}$. Laboratory evaluation of differential attraction of Culex pipiens pallens to the volatiles of flowers, fruits, and seed pods. J Asia-Pac Entomol. 2017;20:1372-6.

34. Stoutamire W. Mosquito pollination of Habenaria obtusata. Mich Bot. 1968;7:203-12 
35. Thien L. Mosquito pollination of Habenaria obtusata (Orchidaceae). Am J Bot. 1969;56:232-7

36. Brantjes NBM, Leemans JAAM. Silene otites (Caryophyllaceae) pollinated by nocturnal lepidoptera and mosquitoes. Acta Bot Neerlandica. 1976;25:281-95.

37. Peach DAH, Gries G. Nectar thieves or invited pollinators? A case study of tansy flowers and common house mosquitoes. Arthropod-Plant Interact. 2016;10:497-506.

38. Peach DAH, Gries R, Young N, Lakes R, Galloway E, Alamsetti SK, et al. Attraction of female Aedes aegypti (L.) to aphid honeydew. Insects. 2019;10:43.

39. Verhulst NO, Beijleveld H, Knols BG, Takken W, Schraa G, Bouwmeester $\mathrm{HJ}$, et al. Cultured skin microbiota attracts malaria mosquitoes. Malar J. 2009:8:1-12.

40. Verhulst NO, Qiu YT, Beijleveld H, Maliepaard C, Knights D, Schulz S, et al. Composition of human skin microbiota affects attractiveness to malaria mosquitoes. PLoS ONE. 2011;6:e28991.

41. Busula AO, Takken W, de Boer JG, Mukabana WR, Verhulst NO. Variation in host preferences of malaria mosquitoes is mediated by skin bacterial volatiles. Med Vet Entomol. 2017;31:320-6.

42. Gillies M. The role of carbon dioxide in host-finding by mosquitoes. Bull Entomol Res. 1980;70:525-32.

43. Schreck CE, James J. Broth cultures of bacteria that attract female mosquitoes. Mosq News. 1968;28:33-8.

44. Trexler JD, Apperson CS, Zurek L, Gemeno C, Schal C, Kaufman M, et al. Role of bacteria in mediating the oviposition responses of Aedes albopictus (Diptera: Culicidae). J Med Entomol. 2003:40:841-8.

45. Lindh JM, Borg-karlson A, Faye I. Transstadial and horizontal transfer of bacteria within a colony of Anopheles gambiae (Diptera: Culicidae) and oviposition response to bacteria-containing water. Acta Trop. 2008;107:242-50

46. Ponnusamy L, Xu N, Nojima S, Wesson DM, Schal C, Apperson CS. Identification of bacteria and bacteria-associated chemical cues that mediate oviposition site preferences by Aedes aegypti. PNAS. 2008;105:9262-7.

47. Müller H. Die Befruchtung der Blumen durch Insekten. Leipzig: Wilhelm Engelmann; 1873.

48. Andersson $1 \mathrm{H}$, Jaenson TG. Nectar feeding by mosquitoes in Sweden, with special reference to Culex pipiens and Cx torrentium. Med Vet Entomol. 1987;1:59-64.

49. Staley JT, Konopka A. Measurement of in situ activities of nonphotosynthetic microorganisms in aquatic and terrestrial habitats. Annu Rev Microbiol. 1985:39:321-46.

50. Barnett JA. A history of research on yeasts 12: medical yeasts part 1 Candida albicans. Yeast. 2008;25:385-417

51. Bensasson D, Dicks J, Ludwig JM, Bond CJ, Elliston A, Roberts IN, et al. Diverse lineages of Candida albicans live on old oaks. Genetics. 2019;211:277-88.

52. Braks MAH, Takken W. Incubated human sweat but not fresh sweat attracts the malaria mosquito Anopheles gambiae sensu stricto. J Chem Ecol. 1999;25:663-72.

53. Takken W, Verhulst NO. Chemical signaling in mosquito-host interactions: the role of human skin microbiota. Curr Opin Insect Sci. 2017;20:68-74.

54. Galen C, Kaczorowski R, Todd SL, Geib J, Raguso RA. Dosage-dependent impacts of a floral volatile compound on pollinators, larcenists, and the potential for floral evolution in the Alpine Skypilot Polemonium viscosum. Am Nat. 2011;177:258-72.

55. Kenney A, Cusick A, Payne J, Gaughenbaugh A, Renshaw A, Wright J, et al. The potential for flower nectar to allow mosquito to mosquito transmission of Francisella tularensis. PLOS ONE. 2017;12:1-12.

56. Belisle M, Peay KG, Fukami T. Flowers as islands: spatial distribution of nectar-inhabiting microfungi among plants of Mimulus aurantiacus, a hummingbird-pollinated shrub. Microb Ecol. 2012;63:711-8.

57. Ushio M, Yamasaki E, Takasu H, Nagano AJ, Fujinaga S, Honjo MN, et al. Microbial communities on flower surfaces act as signatures of pollinator visitation. Sci Rep. 2015;5:1-7.

58. Babcock T, Borden JH, Gries R, Carroll C, Lafontaine JP, Moore M, et al. Inter-kingdom signalling — symbiotic yeasts produce semiochemicals that attract their yellowjacket hosts. Entomol Exp Appl. 2019;167:220-30.

59. Babcock T, Borden J, Gries R, Carroll C, Moore M, Gries G. Lachancea thermotolerans, a yeast symbiont of yellowjackets, enhances attraction of three yellowjacket species (Hymenoptera: Vespidae) to fruit powder. Environ Entomol. 2018. https://doi.org/10.1093/ee/nvy139.

60. Vitanović E, Aldrich JR, Winterton SL, Boundy-Mills K, Lopez JM, Zalom FG. Attraction of the green lacewing Chrysoperla comanche (Neuroptera: Chrysopidae) to yeast. J Chem Ecol. 2019:45:388-91.

61. Hranilovic A, Bely M, Masneuf-Pomarede I, Jiranek V, Albertin W. The evolution of Lachancea thermotolerans is driven by geographical determination, anthropisation and flux between different ecosystems. PLoS ONE. 2017; 12:e0184652.

62. Santo DE, Galego L, Gonçalves T, Quintas C. Yeast diversity in the Mediterranean strawberry tree (Arbutus unedo L.) fruits' fermentations. Food Res Int. 2012:47:45-50.

63. Hranilovic A, Gambetta JM, Schmidtke L, Boss PK, Grbin PR, MasneufPomarede I, et al. Oenological traits of Lachancea thermotolerans show signs of domestication and allopatric differentiation. Sci Rep. 2018;8:14812.

64. Vannette RL, Gauthier M-PL, Fukami T. Nectar bacteria, but not yeast, weaken a plant-pollinator mutualism. Proc R Soc B Biol Sci. 2012;280:20122601

65. Orford KA, Vaughan IP, Memmott J. The forgotten flies: the importance of non-syrphid Diptera as pollinators. Proc R Soc B Biol Sci. 2015;282:20142934-20142934.

66. Rader R, Bartomeus I, Garibaldi LA, Garratt MPD, Howlett BG, Winfree R, et al. Non-bee insects are important contributors to global crop pollination. Proc Natl Acad Sci. 2016:113:146-51.

67. Klecka J, Hadrava J, Biella P, Akter A. Flower visitation by hoverflies (Diptera: Syrphidae) in a temperate plant-pollinator network. PeerJ. 2018;6:e6025

68. Ssymank A, Kearns CA, Pape T, Thompson FC. Pollinating flies (Diptera): a major contribution to plant diversity and agricultural production. Biodiversity. 2008:9:86-9.

69. Davis TS, Landolt PJ. A survey of insect assemblages responding to volatiles from a ubiquitous fungus in an agricultural landscape. J Chem Ecol. 2013;39:860-8

70. Rose MD, Winston F, Hieter P. Methods in yeast genetics. New York: Cold Spring Harbor Laboratory Press; 1990.

71. Takai K, Horikoshi K. Rapid detection and quantification of members of the Archaeal community by quantitative PCR using fluorogenic probes. Appl Environ Microbiol. 2000;66:5066-72.

72. Kurtzman CP, Robnett CJ. Identification of clinically important ascomycetous yeasts based on nucleotide divergence in the $5 \mathrm{~J}$ end of the largesubunit (26S) ribosomal DNA gene. J Clin Microbiol. 1997:35:1216-23.

73. Zara G, Ciani M, Domizio P, Zara S, Budroni M, Carboni A, et al. A cultureindependent PCR-based method for the detection of Lachancea thermotolerans in wine. Ann Microbiol. 2014;64:403-6.

74. Altschul S, Gish W, Myers E, Lipman D. Basic local alignment search tool. J Mol Biol. 1990:215:403-10.

75. Claus D, Berkeley RCW. Genus Bacillus. In: Sneath PHA, Mair NS, Sharpe ME, Holt JG, editors. Manual of systematics bacteriology. Baltimore: Williams and Wilkins; 1986. p. 1104-39.

76. Priest FG. Systematics and Ecology of Bacillus. In: Sonenshein A, Hoch J, Losick R (eds) Bacillus subtilis and other gram-positive bacteria. American Society of Microbiology; 1993. p. 3-16. doi:https://doi.org/10.1128/97815 55818388.ch1.

77. Senses-Ergul S, Ágoston R, Belák Á, Deák T. Characterization of some yeasts isolated from foods by traditional and molecular tests. Int J Food Microbiol. 2006;108:120-4.

78. Aruwa C, Olatope S. Characterization of Bacillus species from convenience foods with conventional and API kit method: a comparative analysis. J Appl Life Sci Int. 2015:3:42-8.

79. Welker NE, Campbell LL. Unrelatedness of Bacillus amyloliquefaciens and Bacillus subtilis. J Bacteriol. 1967:94:7.

80. Venkateswaran K. Bacillus nealsonii sp. nov., isolated from a spacecraftassembly facility, whose spores are gamma-radiation resistant. Int J Syst Evol Microbiol. 2003;53:165-72.

81. Chittpurna, Singh PK, Verma D, Pinnaka AK, Mayilraj S, Korpole S. Micrococcus lactis sp. nov., isolated from dairy industry waste. Int J Syst Evol Microbiol. 2011;61:2832-6. 
82. Vaughan-Martini A, Martini A. Determination of ethanol production. In: The yeasts. Fourth. Elsevier, Amsterdam; 1998. p. 107. doi:https://doi. org/10.1016/B978-044481312-1/50017-4.

83. Adams R. Identification of essential oils by ion trap mass spectroscopy San Diego: Academic Press; 1989.

\section{Publisher's Note}

Springer Nature remains neutral with regard to jurisdictional claims in published maps and institutional affiliations.
Ready to submit your research? Choose BMC and benefit from:

- fast, convenient online submission

- thorough peer review by experienced researchers in your field

- rapid publication on acceptance

- support for research data, including large and complex data types

- gold Open Access which fosters wider collaboration and increased citations

- maximum visibility for your research: over 100M website views per year

At BMC, research is always in progress.

Learn more biomedcentral.com/submissions 